\title{
Potential pathogenic aspects of denture plaque
}

\section{COULTHWAITE and J. VERRAN}

School of Biology, Chemistry \& Health Science, Manchester Metropolitan University, Manchester, UK

Accepted: 13 November 2007

\section{Oral health of the elderly}

Oral healthcare is not adequately considered in most protocols outlining maintenance of personal hygiene and general health for the elderly in hospitals, long-term care units or intensive care units, and is poorly addressed by health policies aimed at the community-living elderly. ${ }^{1-3}$ Oral health, although rarely life-threatening, plays an essential role in the quality of life, ${ }^{4}$ management of medical problems, nutrition, and social interaction of the elderly. ${ }^{5}$ High-risk groups for oral diseases include old people in institutions or those who are functionally dependent for activities for daily living. ${ }^{6}$

There have been few studies on the provision of oral care for denture-wearing populations. This is particularly important for the debilitated elderly receiving domiciliary visits (or not), those in long-term institutional care such as hospitals, and those in nursing homes who depend on healthcare personnel or family members for their oral care $^{1,3,7,8}$ Stroke results in coordination, sensory or cognitive deficits and has an impact on independent oral care, yet in only 49/70 stroke-care settings surveyed were staff expected to clean patients' dentures. ${ }^{8}$

In a single study, $96 \%$ of nursing home staff questioned felt that oral healthcare of the elderly was very important and $96.2 \%$ indicated dentures should be cleaned at least once a day and rinsed after every meal. ${ }^{9}$ However, this is only an indication of positive thinking and does not indicate implementation. Intervention on oral cleanliness of longterm hospitalised elderly in a single study led to improved denture hygiene and the recommendation that organised oral health education of nursing staff should receive more attention. ${ }^{10}$

Malnutrition in the elderly is a particular problem in institutional settings, with reported frequencies in geriatric patients of $30-60 \% .{ }^{11}$ An association has been reported between malnutrition and the presence of oral candidosis, ${ }^{11}$ which in turn results in mucosal lesions, decreased energy intake, and subsequently worsening nutritional status. The provision of daily oral care for nursing home residents can

\section{ABSTRACT}

Oral health status declines with age and as a result the need for removable prostheses increases. Oral health is a reflection of one's general health, affecting the ability of an individual to eat and speak, and contributes significantly to a sense of confidence and well-being. Currently, there are 15 million denture wearers in the UK, representing a significant consumer base and a special healthcare consideration. The microbiology of denture plaque has received little attention in comparison with dental plaque, yet it differs in location and composition. Denture plaque and poor denture hygiene is associated with stomatitis (Candida infection), may also serve as a reservoir of potentially infectious pathogens, and may contribute to oral malodour and to caries and periodontitis in people who have remaining natural teeth. Oral bacteria have been implicated in bacterial endocarditis, aspiration pneumonia, gastrointestinal infection and chronic obstructive pulmonary disease, among others, and dentures offer a reservoir for microorganisms associated with these infections. An effective oral hygiene regimen is important to control denture plaque biofilm and contributes to the control of associated oral and systemic diseases.

KEY WORDS: Denture.

Plaque.

Oral health.

prevent aspiration pneumonia, improve appetite, and enhance quality of life. Despite this, in a single study of an acute-care long-term hospital for the elderly, only $30 \%$ of caregivers interviewed had received specific training in elderly oral care, ${ }^{6}$ accounting for the lack of implementation of oral hygiene protocols.

An unhygienic oral environment, resulting in plaqueassociated oral diseases such as inflammatory gingivitis and periodontitis, can affect systemic health negatively and may contribute to initiation and/or progression of certain lung diseases..$^{12}$ Most bacterial pneumonias occur by aspiration of bacteria colonising the oropharynx or upper gastrointestinal tract of the patient, and the debilitated are at the greatest risk for developing pneumonia. The most commonly isolated organisms from invasive bronchial specimens, blood cultures, pleural fluid and serology of intubated nursing home residents were Staphylococcus aureus (29\%), enteric Gram-negative rods (15\%, predominantly Klebsiella pneumoniae and Escherichia coli), Streptococcus pneumoniae (9\%) and Pseudomonas aeruginosa (4\%), with a fatality rate of $57 \% .^{13}$

In a single study, potential respiratory pathogens colonised dental plaque in $64.5 \%$ of the dependent elderly surveyed, thus plaque was considered a specific reservoir for colonisation and subsequent aspiration pneumonia of the 

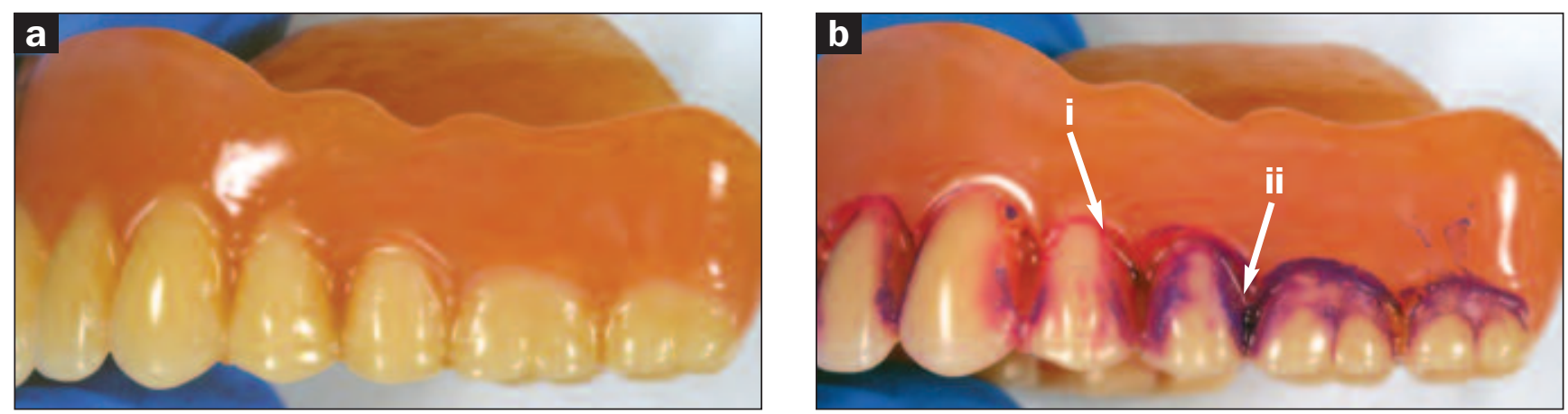

Fig. 1. Plaque on a complete maxillary denture: (a) before and (b) after disclosing with PlaqueFinder, showing plaque accumulation at (i) the tooth-gum interface and (ii) interproximal regions, red indicating old and blue newer plaque.

dependent elderly. ${ }^{14}$ Approximately $60 \%$ of cases of hospitalacquired pneumonia are caused by aerobic Gram-negative bacteria, particularly the Enterobacteriaceae; however, Staphylococcus aureus and other Gram-positive cocci including Streptococcus pneumoniae have emerged as important isolates. ${ }^{15}$ Literature review suggests respiratory pathogens preferentially colonise teeth or dentures, rather than soft tissue. ${ }^{16,17}$ Thus, it is important that the aspiration of opportunistic pathogens in the elderly is kept to a minimum through effective oral healthcare practices.

A recent report on ageing by the Wellcome Trust ${ }^{18}$ omits any mention of oral health, and this is a major failing as oral health affects diet and nourishment, social interactions and self-confidence, and has been shown to be an important risk factor in associated systemic diseases. Further studies are required on the oral health of the elderly, as this is an important yet neglected area of geriatric medicine and dentistry. It is important to ensure that the extra years of life that people are gaining are as healthy, productive and enjoyable as possible. As lifespan lengthens, there is a fear that so too will the period of illness at its end. ${ }^{18}$

\section{Denture-wearing population}

Preservation of the dentition into old age has become more common in recent decades, ${ }^{19}$ and this can be used as an indicator of the oral health of a population. As a result of improvements in health and medical care, life expectancy is continuing to increase, ${ }^{20}$ resulting in an increasingly elderly population in many developed countries. In Japan, it is predicted that the elderly will comprise over $25 \%$ of the total population by $2025 .^{21}$

Oral health status declines with age, and as a result the need for removable prostheses increases. Thus, there will be a denture-wearing population for some time to come. Removable prostheses include full or partial maxillary (upper jaw) or mandibular (lower jaw) dentures. Although the proportion of people reliant on dentures is decreasing, over $25 \%$ of people in the UK wear complete or partial dentures. ${ }^{19}$ Currently, there are 15 million denture wearers in the UK, with 120,000 edentulous people. Of these, approximately $40 \%$ wear full dentures, $20 \%$ wear one full denture only, $17 \%$ wear one full and one partial denture, and $23 \%$ wear partial dentures only. ${ }^{22}$

Although over $69 \%$ of edentate people in the UK are aged over 65 years, $^{19}$ the overall population wearing dentures presents a wide age and health range. Many of these individuals are healthy and active, while others are infirm. The former represent a significant consumer base, primarily for aesthetic purposes, while the latter require simple and effective non-mechanical methods for maintaining oral hygiene such that the debilitated elderly (and/or their carers) can maintain control of their oral healthcare. ${ }^{22}$

\section{Oral environment in denture wearers}

The oral cavity provides a diverse range of surfaces including soft, shedding, non-keratinised buccal mucosal epithelia, the keratinised mucosa of the gums, the specialised, highly papillated mucosa of the tongue, and the hard, non-shedding surfaces of the teeth. In comparison with the dentate individual, the mouth of the denture wearer presents additional hard, non-shedding areas and new environments (tissue-fitting surfaces) to support the growth of microorganisms and the development of plaque. Dentures accumulate plaque, stain and calculus in a way similar to natural teeth (Fig. 1). ${ }^{23}$

There are microbiological problems associated specifically with denture wearing that have been relatively neglected. These include the aesthetic appearance of the false teeth (e.g., presence of staining and calculus; Fig. 2), oral/denture hygiene, damage to oral tissues, caries, gingivitis and periodontitis in the remaining teeth of partially dentate subjects where plaque builds up at the abutment site (Fig. 3), ${ }^{24-26}$ denture-related stomatitis and halitosis. The denture may also act as a reservoir of infection for respiratory and systemic opportunistic pathogens, ${ }^{16,17}$ and presents a niche for antibiotic-resistant bacteria. ${ }^{27,28}$

Xerostomia (dry mouth) is common in elderly populations, affecting denture retention and the microbial flora. Loss of fit of the prosthesis due to alveolar bone resorption (resulting from the loss of adjacent natural teeth) may increase inflammation and also affect denture retention during speech and eating. There is also a lack of work on partial denture wearers to compare the adjacent microbial plaque biofilms on the dentures and remaining natural teeth.

Dentures are made of synthetic polymers, primarily polymethylmethacrylate (PMMA), and sometimes are used with soft liners and tissue conditioners to improve comfort and fit and to reduce irritation on the mucosa. Denture soft lining materials such as silicone are flexible in order to provide cushioning of the hard denture acrylic base and hence are more permeable with more porous structures and 

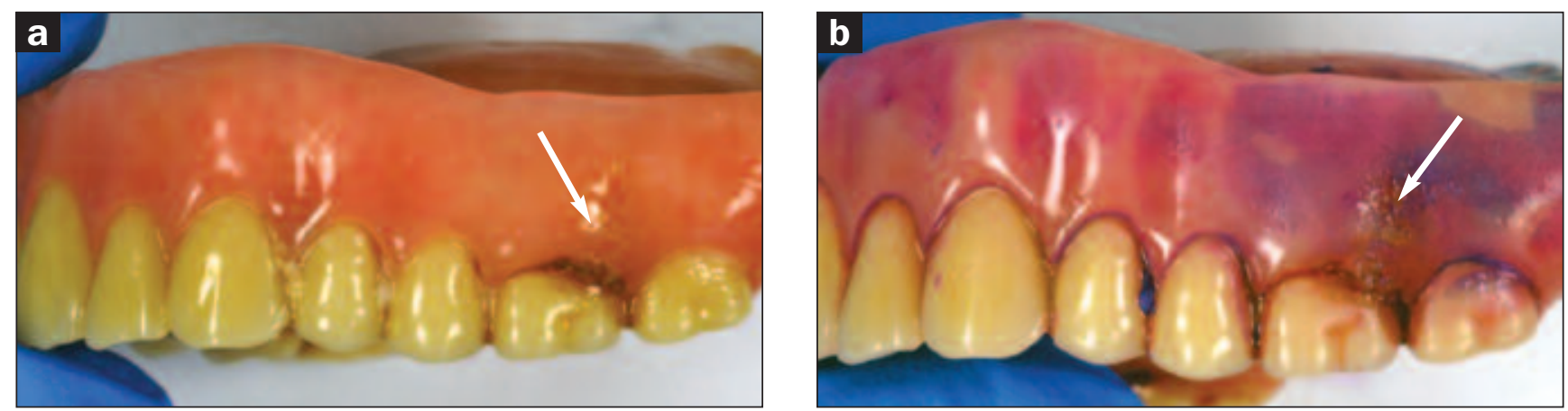

Fig. 2. Plaque and calculus (arrowed) on the buccal surface above the molars of a complete maxillary denture (a) before and (b) after disclosing with PlaqueFinder.

more depressions in which cells may be retained. ${ }^{29}$ Therefore, these silicone materials are more susceptible to microbial colonisation and penetration, resulting in deterioration and loss of functional properties. ${ }^{30}$

Modification of denture materials to reduce attachment is an active area of dental research, although little has yet reached the market. For example, reduced surface roughness $^{31}$ and hydrophobic modification ${ }^{32}$ of silicone softliners can decrease adhesion and subsequent colonisation, particularly by Candida albicans.

Removable dentures can undergo harsher cleaning regimes than is safe for the natural dentition because they can be removed from the mouth. However, many denture wearers do not remove their dentures for cleaning, and this is a major periodontitis and caries risk in partial denture wearers ${ }^{24}$ and is also associated with increased prevalence of stomatitis in complete denture wearers. ${ }^{33}$

Research highlighting plaque accumulation 'hot spots', demonstrating poor oral hygiene, and the colonisation of potential pathogens on the dentures might encourage a change in the perception of denture wearers regarding their oral hygiene procedures. There are, therefore, fundamental benefits for both complete and partial denture wearers in terms of the detection and subsequent removal of plaque. Education on, and maintenance of, good oral hygiene and health status is essential for denture wearers (and/or their carers).

It is important to distinguish between the bacterial species associated with health and disease, but many known pathogenic bacteria are present in a healthy mouth, ${ }^{34}$ and,
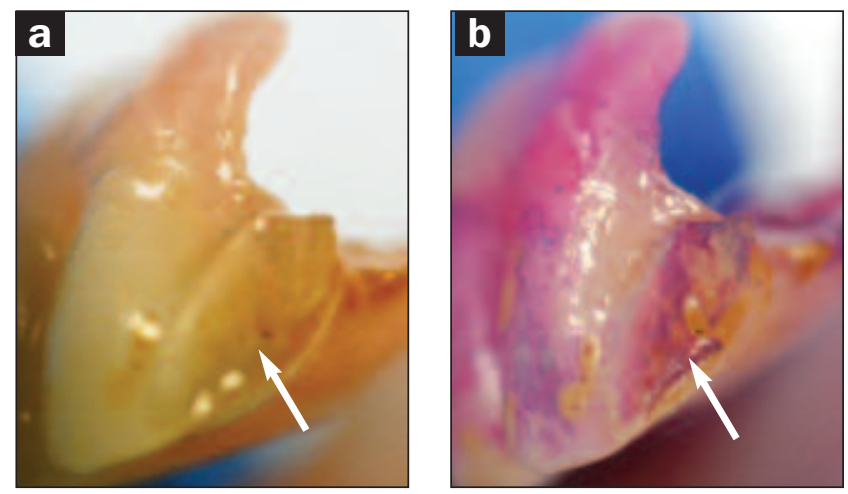

Fig. 3. Partial maxillary denture (a) before and (b) after disclosing with PlaqueFinder showing plaque accumulations (arrows) on the denture tooth at the abutment site that contacts the remaining natural teeth in the mouth. according to the ecological plaque hypothesis, ${ }^{35}$ it may be the proportions of pathogens present that cause the change from health to disease, rather than the presence or absence of particular species. It is also important to know which microorganisms are present in the oral cavity for diagnosis and rational treatment of systemic as well as oral diseases. ${ }^{36}$

Plaque control on the fitting surface is difficult to maintain, ${ }^{3,37-39}$ due to the rough surface topography where plaque retention and accumulation is enhanced. ${ }^{30}$ This highlights the need for effective chemical cleansers coupled with physical removal.

The bacterial flora of saliva in edentulous patients wearing dentures may be derived from bacteria colonising the dentures as well as those from the oral mucous membranes, mainly the tongue. ${ }^{40}$ The natural flow of saliva, and mastication, detaches microbes not attached firmly to oral surfaces, but the environment beneath a denture will be less susceptible to these properties. Types of medication can reduce salivary flow rate, which, along with a decrease in host defences that may occur in old age, ${ }^{41}$ could contribute to the increased isolation of staphylococci and enterobacteria (not typical oral species) from the oral cavity of the elderly.

Complete denture wearers lack gingival crevices, hence gingival crevicular fluid (GCF) and periodontal disease are absent. Therefore, the absence of periodontal species might be anticipated. However, in the edentulous patient, serum released during inflammation resulting from mucosal irritation by ill-fitting dentures may support a more diverse community on the denture, with increased growth of more fastidious anaerobes in the nutrient-rich niche created. Few studies have isolated obligate anaerobes from denture plaque. Although this may be due to these microorganisms not being a focus in these studies, the more demanding nutritional and atmospheric requirements necessary for their recovery from clinical samples may be an additional factor that contributes to reduced proportions in denture plaque compared to mature dental plaque.

\section{Denture plaque composition}

The oral flora comprises a diverse group of microorganisms including bacteria, fungi, mycoplasmas, protozoa and viruses. Bacteria predominate, with an estimate of over 600 different species present in the oral cavity; ${ }^{42}$ however, only half of these species can be cultured in the laboratory. ${ }^{43,44}$ This will be true for both dentate and edentate individuals.

Denture plaque is a dense, complex heterogeneous layer 
of microorganisms and their metabolites, and it contains more than $10^{11}$ organisms/g (wet weight). ${ }^{45}$ Denture plaque develops from adherence, aggregation and growth of microbes from saliva, oral mucosa and possibly fingers in the absence of adequate denture hygiene, and derives nutrients from saliva, oral mucosa and the diet. ${ }^{39}$ Plaque accumulates preferentially at stagnant sites offering protection from flow and mechanical removal forces in the mouth, ${ }^{46}$ and the denture provides many such sites.

Plaque was visible before disclosing on over $50 \%$ of dentures assessed in two recent studies, ${ }^{47,48}$ indicating a poor level of oral hygiene among denture wearers. Plaque on dentures acts as a film for stain deposition ${ }^{23}$ and, if left in a particular area, may calcify and become 'tartar' or calculus (Fig. 2), which requires dental scaling for removal. ${ }^{49}$

The microbiology of denture plaque has received little attention in comparison to dental plaque (Table 1) yet it differs in terms of location (the most problematic denture plaque occurs on the maxillary fitting surface) and composition (increased likelihood of the presence of yeast) ${ }^{26}$ (Fig. 4a), but the general composition, particularly of obligate anaerobes, is ill-defined. Of the total publications containing the keywords dental and denture, 'dental' publications represent around $90 \%$, and 'denture' publications around $10 \%$ - a proportion that is decreasing. With plaque as a keyword, again 'dental' publications predominate (around $95 \%$ ), while including the term microbiology results in a further decrease in the proportion of denture publications to just 3\%. Numerous cultural studies have reported the diversity of the resident oral microflora in dentate individuals, and it is likely to be the same for denture wearers, but further studies are warranted.

There have been relatively few studies on denture plaque microbiology, the bulk being carried out in the 1980s on small subject groups, with few recent studies. ${ }^{26}$ The majority of the literature on denture plaque focuses on the aetiological agent of denture-related stomatitis, Candida albicans (Fig. 4a), and associated causative factors (i.e., poor denture hygiene and subsequent plaque accumulation). ${ }^{26}$ There is general agreement that denture plaque composition is broadly similar to that of dental plaque, ${ }^{26,37}$ with Grampositive cocci and short rods predominating, ${ }^{37,38,50-52}$ whereas Gram-negative rods are relatively few in number. ${ }^{50,51,53}$

Plaque microflora varies between individuals and
Table 1. Number of papers identified using the keywords 'dental' and 'denture' in PubMed (www.ncbi.nlm.nih.gov/sites/entrez) over the last 30 years (accessed 20 October 2007).

\begin{tabular}{lccc}
\hline & & & \\
& Dental & Denture & Total \\
\hline $\mathbf{5}$ Years & & & \\
keyword & 39325 & 2978 & 42303 \\
\hline \& plaque & 2377 & 113 & 2490 \\
\hline \& microbiology & 917 & 29 & 946 \\
\hline $\mathbf{1 0}$ Years & & & \\
\hline keyword & 73589 & 5793 & 79382 \\
\hline \& plaque & 4531 & 230 & 4761 \\
\hline \& microbiology & 1845 & 61 & 1906 \\
\hline 20 Years & & & \\
\hline keyword & 149671 & 15105 & 164776 \\
\hline \& plaque & 9581 & 521 & 10102 \\
\hline \& microbiology & 3801 & 127 & 3928 \\
\hline 30 Years & & & \\
\hline keyword & 213603 & 26682 & 240285 \\
\hline \& plaque & 13567 & 782 & 14349 \\
\hline \& microbiology & 5239 & 173 & 5412 \\
\hline
\end{tabular}

between sites in the mouth and on the denture, where differences between the buccal flange, denture tooth, tooth gum interface and the fitting surface have been identified. ${ }^{26}$ Ass et al..$^{54}$ reported that most sites contained 20-30 different predominant (Fig. 4b) bacterial species. This is probably a vast underestimate due to culture compared to molecular analysis techniques.

The predominant cultivable microflora of denture plaque includes Streptococcus spp. (S. sanguinis [formerly S. sanguis], S. oralis, S. anginosus, S. salivarius), Staphylococcus spp. (S. aureus, S. epidermidis), Gram-positive rods (Actinomyces spp. [A. israelii, A. naeslundii, A. odontolyticus], lactobacilli, Propionibacterium spp.), Veillonella spp., Gram-negative rods and yeasts. . $3,37,39,53,55,56$ The apparent absence of Streptococcus mutans as a predominant microbial species in denture plaque is important because it can predominate in dental plaque, and is aetiologically associated with dental caries.

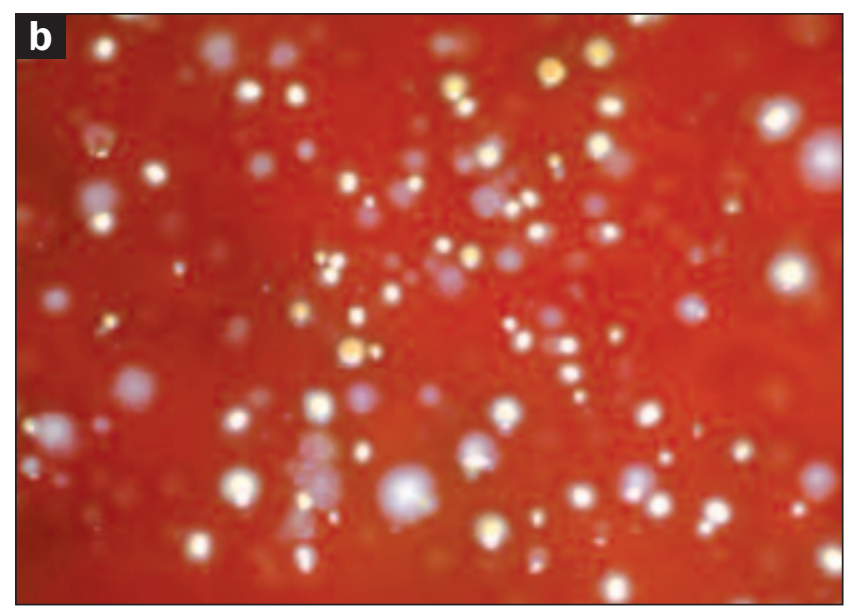

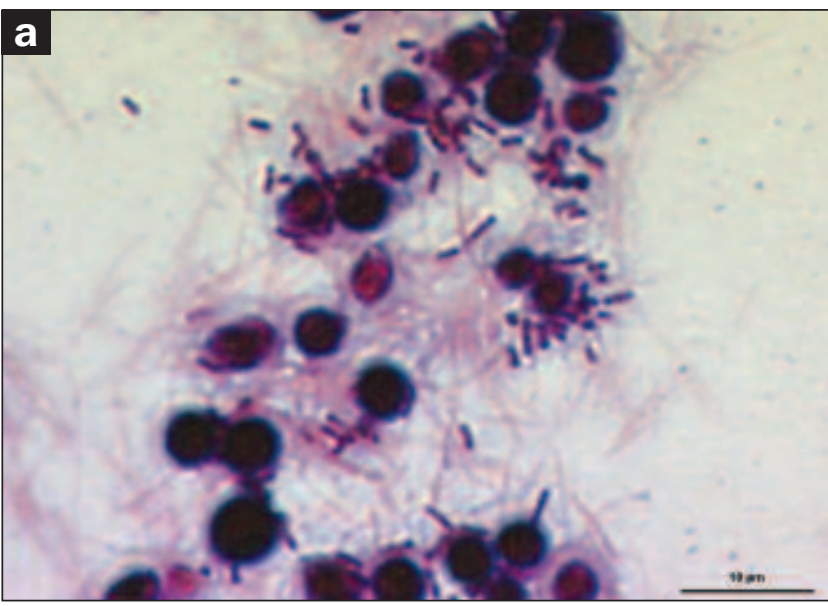

Fig. 4. a) Gram stain of a smear of denture plaque showing yeast blastospores, Gram-positive rods and long, slender Gram-negative rods. b) Denture plaque mixed colonies produced on fastidious anaerobe agar with $6 \%$ horse blood after 72 -h anaerobic incubation. 

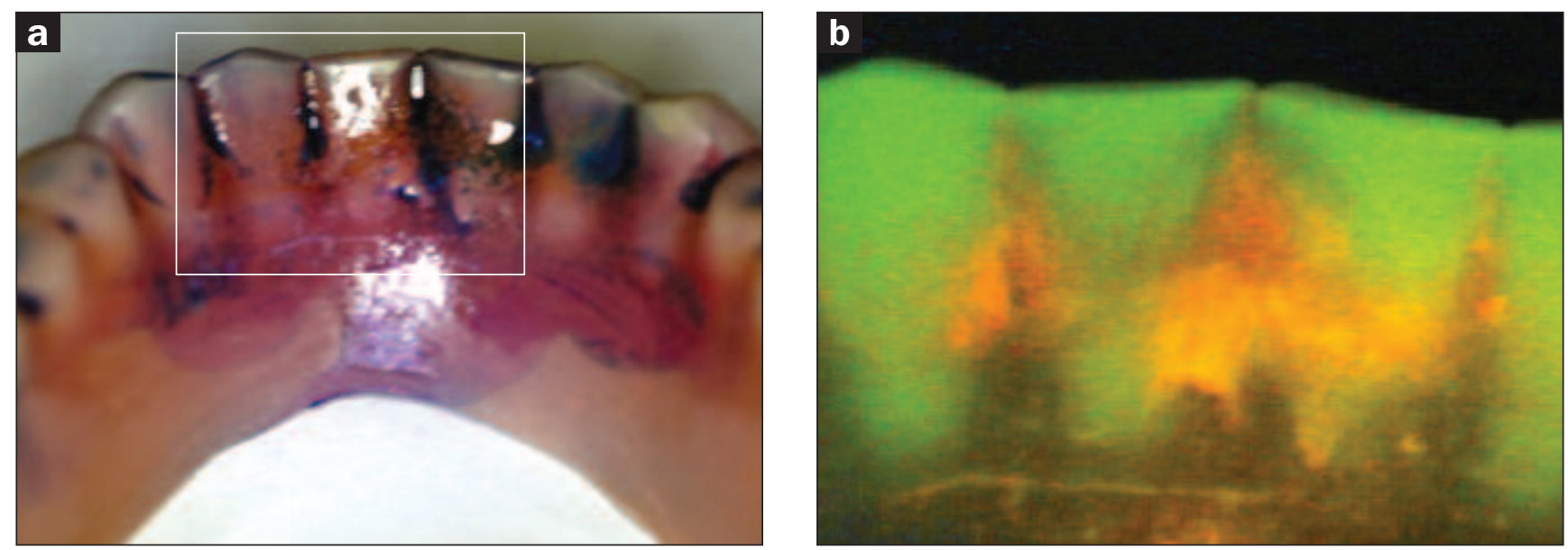

Fig. 5. Lingual surface of a mandibular denture (a) stained with PlaqueFinder and (b) QLF image of highlighted area in (a) showing red fluorescence of the mature plaque biofilm.

In the relatively stagnant area on the tissue-fitting surface of dentures, plaque tends to be more acidogenic, thus favouring streptococci and Candida spp., which is found most frequently on this surface of the denture. ${ }^{26,57}$ In addition, a higher nutrient concentration, low salivary flow rates and roughened topography support and protect plaque. $^{22}$

Denture plaque in comparison to dental plaque was reported to have a large proportion of obligate anaerobic Actinomyces spp. (A. israelii), low proportions of Gramnegative rods and the regular presence of the skin bacterium Staphylococcus aureus..$^{34,37,55}$ In a single study of denture plaque, $27 \%$ of subjects were colonised with S. aureus, of which only $1 \%$ were methicillin-resistant $S$. aureus (MRSA) ${ }^{28}$ Although this may indicate low clinical significance, it is one of few studies specifically targeting MRSA detection.

No specific investigations into the contribution of Gramnegative obligate anaerobes to denture plaque have been reported. The term Gram-negative rods tends to be used as a blanket term, ${ }^{50,51,53}$ yet this group may be important in associated systemic diseases and periodontal diseases in partial denture wearers, and are known to contribute to malodour production. The presence of particular species, notably the periodontal pathogens, pigmented Prevotella species and Porphyromonas gingivalis, is rarely reported. There is no evidence in the literature to indicate that P. gingivalis has been detected from denture plaque, ${ }^{56}$ yet Prevotella melaninogenica ${ }^{56}$ and $P$. intermedia $a^{38}$ have been isolated. No study of the tongue flora of denture wearers could be found in the literature.

Few molecular studies have been applied to plaque profiling. A preliminary study has demonstrated the successful application of polymerase chain reactiondenaturing gradient gel electrophoresis (PCR-DGGE) to profile bacterial communities present in healthy denture plaque. $^{58}$ This technique has been applied to study the bacterial communities of dental plaque in health and gingivitis $^{59}$ and in endodontic infections, ${ }^{60}$ among others. The DGGE profiles showed a considerable degree of variability between plaque samples from different sites on the same denture, and from different subjects. ${ }^{58}$ Importantly, DGGE gave information about community composition that could not be derived using culture isolation techniques. ${ }^{58}$ A comparison between profiles of 'pathogenic' denture plaque in comparison with 'healthy' denture plaque could prove useful.

\section{Denture plaque assessment}

Measurement and assessment of plaque can provide valuable information about an individual's oral health status, hygiene procedures, assessment of disease prognosis and assessment of new treatments or products. Methods used for assessing plaque quantity have included dry or wet weight measurement, biochemical assays, oxygen consumption assays, microbiological counts and visual or planimetric assessments of plaque coverage or biofilm thickness in situ. ${ }^{61-66}$

Fluorescence detection is a non-contact, non-destructive technique that has received increased attention due to its high sensitivity and specificity. ${ }^{67}$ The Quantitative Lightinduced Fluorescence (QLF) imaging system (Inspektor Research Systems, BV) is a special dental diagnostic tool that has been used for in vivo and in vitro quantitative assessment of dental caries, tooth whitening, bacterial activity, calculus, staining, and dental plaque. ${ }^{68,69}$ The technique is based on the autofluorescence of teeth, which, when illuminated with low-power visible blue light, emit in the green part of the spectrum. Fluorescence light irradiation reveals differences in enamel opacity (demineralised and sound enamel), making earlier caries lesion detection possible. In addition, QLF can be used to indicate the presence of plaque on teeth, as the microorganisms fluoresce to some extent during the process.

Denture plaque can be detected using the QLF system, ${ }^{70}$ with potential implications in oral hygiene assessment. Areas of red and green fluorescence have been observed from denture and dental plaque in vivo under QLF illumination, and differences between the microbial species at these sites has been demonstrated by culture-dependent ${ }^{70}$ and -independent ${ }^{58}$ techniques. The detection of red fluorescent plaque using the QLF system is indicative of black pigmented obligate anaerobes, and thus mature plaque, ${ }^{70}$ highlighting plaque traps (Fig. 5), areas of stagnation such as the fitting surface (Fig. 6), and proximity to salivary duct openings (Fig. 7). Thus, detection of red plaque deposits using the QLF system indicates areas of 

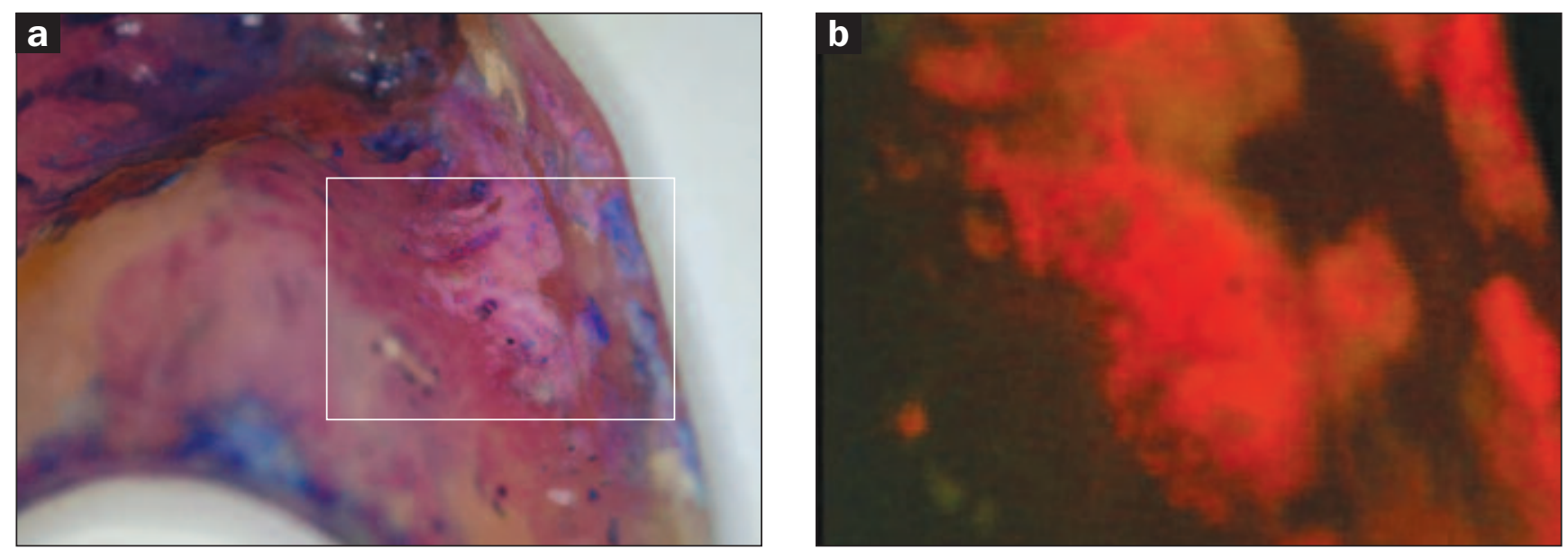

Fig. 6. Fitting surface of a maxillary denture (a) stained with PlaqueFinder and (b) QLF image of highlighted area in (a) showing red fluorescence of the mature plaque biofilm.

plaque accumulation/mature plaque, and highlights target areas for hygiene procedures.

\section{Problems associated with denture plaque}

\section{Stomatitis and oral candidosis}

Most of the literature on denture plaque focuses on Candida albicans and its association with denture stomatitis. Candida is isolated more frequently from denture plaque than from dental plaque. ${ }^{71-73}$ The most important source of Candida species in humans is endogenous: candidoses arise in subjects predisposed by illness, debility or local reduction in host resistance to an overgrowth of their own yeast flora. ${ }^{74}$

Candidosis is the most common systemic mycosis, ${ }^{75}$ with several species of Candida capable of causing infection. Adhesion enables Candida to resist the flushing action of saliva, and is the first stage in the process leading to colonisation and infection, ${ }^{76}$ making it an important virulence factor. The rate of adhesion of Candida spp. isolated from denture plaque to exfoliated buccal epithelial cells has been shown to be very low, ${ }^{77}$ indicating that the major reservoir of Candida is the denture itself, rather than the mucosal epithelia.

Denture-related stomatitis is a condition present in $10-75 \%$ of denture wearers $\mathrm{s}^{7,78-81}$ and often is linked with acute pseudomembranous oral candidosis (thrush). ${ }^{82}$ The main reservoirs of $C$. albicans and related species are the fitting surface of the denture $\mathrm{r}^{53,57,71,83}$ and soft denture lining material, where present. ${ }^{29}$ Oral candidosis development may be promoted by poorly fitting dentures and poor denture hygiene, ${ }^{72}$ along with other predisposing factors including age, corticosteroids, broad-spectrum antibiotics and immunosuppression. ${ }^{84}$ Generally, C. albicans is accepted as the main aetiological agent of denture-related stomatitis; ${ }^{71}$ however, several studies have implicated bacteria and poor denture hygiene in the disease process. ${ }^{52,55,57,82}$

Yeasts usually constitute less than $1 \%$ of the total cultivable isolates of denture plaque, ${ }^{37,51}$ yet they contribute a significant mass to the plaque biofilm as a result of their large size compared with bacteria. ${ }^{26}$ It has also been suggested that Candida infection could contribute to caries, root caries and periodontitis of abutment teeth; ${ }^{45}$ thus, reduction of yeast levels is of particular importance to partial denture wearers.

\section{Malodour}

Oral malodour is a common and often distressing condition and is poorly explored in denture wearers. Owing to the artificial nature of the denture, many edentulous patients express concern that they may produce a distinct malodour. ${ }^{85}$ Dirty dentures contribute to malodour, ${ }^{23}$ which is generally acknowledged in the dentate to be caused in part by volatile sulphur compounds (VSCs), including hydrogen sulphide, methyl mercaptan and dimethyl sulphide. ${ }^{86}$ These VSCs cause a fetid or putrid odour and are produced by Gramnegative bacteria, particularly anaerobic species such as Porphyromonas spp., Prevotella spp. and Fusobacterium spp. ${ }^{87,88}$ by proteolytic degradation of sulphur-containing peptides
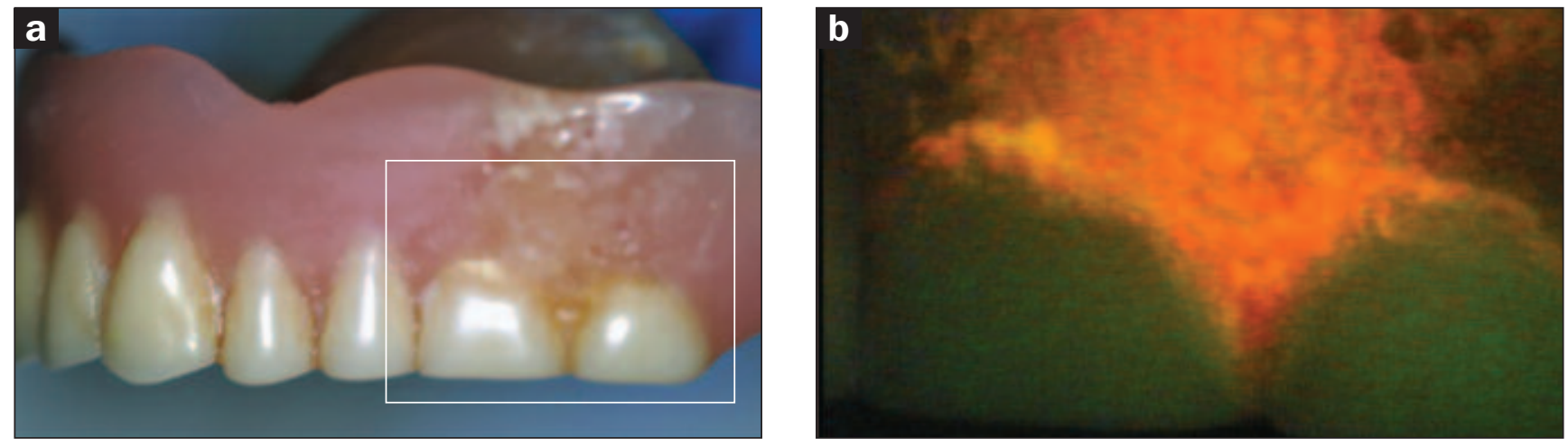

Fig. 7. Maxillary denture 3 buccal surface (a) undisclosed and (b) QLF image of highlighted area in (a) showing red fluorescence. 
and amino acids present in saliva, shed epithelium, food debris, GCF, plaque and blood ${ }^{86}$ These bacteria also have an association with periodontal disease. ${ }^{86,87,89}$ Other Gramnegative bacteria found in denture plaque, such as Klebsiella spp., may be potential pathogens in respiratory or systemic diseases arising from the oral reservoir of microorganisms.

Little work has been published on denture-associated malodour, but many species capable of producing malodorous compounds are found in denture plaque. ${ }^{22}$ Dentures are particularly important causes of oral malodour if they are worn overnight; ${ }^{90}$ thus, frequent plaque removal and denture cleaning is important to reduce dentureassociated malodour. Many denture cleansing products claim breath-freshening properties, yet this has not been investigated specifically. Indeed, it is more likely that any odour is 'masked' rather than reduced. The role of yeasts, decreased salivary flow, the nature of tongue flora in edentulous individuals, colonisation of the denture, and the presence of soft liners on denture-associated malodour are unknown. The profile of denture malodour in the presence and absence of yeast in the plaque as yet is undefined.

\section{Reservoir of infection}

Recently, there has been an increase in the number of studies investigating the link between oral and systemic diseases in the dentate ${ }^{14,91,92}$ and edentate. ${ }^{7,16,21,45}$ Oral bacteria have been implicated in bacterial endocarditis, ${ }^{90}$ aspiration pneumonia, ${ }^{92-94}$ gastrointestinal infection ${ }^{17}$ and chronic obstructive pulmonary disease $^{93}$ among others, and dentures offer a reservoir for microorganisms associated with these infections.

Dentures may spend time in a non-hygienic environment when out of the mouth and may also harbour microorganisms not normally associated with the oral flora, including Streptococcus pneumoniae, Haemophilus influenzae, Neisseria meningitidis, certain Enterobacteriaceae ${ }^{22,26}$ including E. coli, Klebsiella spp. ${ }^{16,83}$ and Pseudomonas spp., and staphylococci including, but rarely, MRSA..$^{27,28}$ Such organisms may be considered respiratory pathogens and have been reported to colonise the denture plaque in $46 \%$ of the dependent elderly. ${ }^{16}$ Hospital and institutionalised denture wearers may be at increased risk of crosscontamination when healthcare workers handling the dentures do not take adequate hygiene measures.

The continuous swallowing or aspiration of microorganisms from denture plaque exposes patients, particularly the immunocompromised host or medicated elderly, to the risks of unexpected infection; ${ }^{21,45}$ thus, the role of the denture in harbouring such organisms may be significant. Respiratory diseases, particularly pneumonia, are responsible for significant morbidity and mortality in human populations. Oral bacteria may be inhaled directly, organisms in plaque shed in the saliva, and small droplets aspirated into the lungs where bacterial enzymes decrease protection against colonisation..$^{93}$

Residents in institutional situations for extended periods of time, such as long-term hospital patients or nursing home residents, have increased exposure to pathogens (including drug-resistant strains), are less likely to have good oral hygiene and are more likely to have poor general health. ${ }^{93} \mathrm{It}$ is reported that a relationship exists between poor oral health, oral microflora and bacterial pneumonia. ${ }^{92,94}$ In order to reduce the load of endogenous microorganisms in the oral cavity, mechanical removal of plaque biofilms is essential. ${ }^{92}$

\section{Hygiene}

Denture plaque and poor denture hygiene are suggested to be the principal causes leading to severe inflammation of the palatal mucosa ${ }^{23,95,96}$ and to denture-related stomatitis, ${ }^{72,78,80,96,97}$ thus indicating the importance of maintaining good denture hygiene and the efficacy of denture cleansing products.

Denture cleanliness is essential to prevent malodour, poor aesthetics and accumulation of plaque and calculus. ${ }^{22,23,96}$ For denture wearers in comparison to the dentate, less attention has been paid to the importance of plaque control and removal..$^{98}$ The change from healthy to diseased plaque may be a natural progression in the absence of adequate hygiene procedures, where a nutrient-rich niche is created..$^{26}$ In the absence of oral hygiene in the dentate, gingivitis ensues, ${ }^{99}$ so, in the absence of denture hygiene, it may follow that denture stomatitis would be equally inevitable. ${ }^{26}$

Only a limited number of people maintain effective oral hygiene, and the majority of denture wearers are failing to keep their dentures clean. ${ }^{1,81,95,100}$ Although it is recommended that dentures be removed at night, ${ }^{25,101}$ this is often not the case, ${ }^{19}$ and wearing dentures overnight has been associated with poor oral heath in comparison to day-wearing of dentures only. ${ }^{24,80}$

Mechanical plaque removal and control and good denture-wearing habits, including regular check-ups, are the most important measures in the prevention and treatment of denture-induced stomatitis. ${ }^{78}$ It has been recommended that denture wearers should be instructed and motivated to brush. ${ }^{23}$ Brushing with a paste or soap is the most common form of denture cleaning, $;^{23,100}$ however, this demands manual dexterity beyond the ability of many geriatric or physically or mentally handicapped individuals.

A denture-cleansing product should be easy to use, remove organic and inorganic plaque deposits effectively, be bactericidal and fungicidal, and non-toxic. ${ }^{102}$ Additionally, it should clean tough stains and control denture odour while being gentle on the acrylic (no whitening or abrading). Currently, commercially available denture cleansers include alkaline peroxides, alkaline hypochlorites, dilute acids (1.6-1.8 $\mathrm{M} \mathrm{HCl}$ or $\mathrm{H}_{3} \mathrm{PO}_{4}$ ), disinfectants and enzymes. Mechanical methods of cleaning dentures include abrasive pastes or powders, microwaving ${ }^{82}$ and ultrasonication. ${ }^{103}$ For elderly denture wearers, chemical soaks are the method of choice..$^{97,104,105}$

Coulthwaite et $a l,^{106}$ developed a model denture plaque biofilm in a constant-depth film fermenter (CDFF) that can be used to evaluate antimicrobial efficacy of denture cleansers in vitro, and showed that a range of commercially available cleansers were equally successful at plaque viability reduction. This provided a more readily accessible plaque consortium than denture plaque, and is more valid than current models using batch cultures of pooled healthy dentate saliva. Although all products were equally successful at total microbial count reduction, cleaning did not reduce Candida spp. levels significantly; ${ }^{106}$ a finding that has significant implications for the ability of these products to act effectively in prevention and control of denture-related stomatitis suffered by the majority of denture wearers at some time. Some denture plaque microorganisms are known to contribute to oral malodour. ${ }^{22}$ During pilot studies, an odour dissimilar to oral malodour, was detected on the prostheses (rather than the breath) ${ }_{1}^{56}$ the nature and origin of which merit further exploration. 
Dental caries (with periodontal disease) is one of the most common human diseases and affects the vast majority of individuals, including partial denture wearers. Bone resorption is a particular problem in denture wearers, resulting in ill-fitting dentures, reduction in structural support, and ultimately the need for new dentures to be fitted. Therefore, detection and characterisation of denture plaque is important for overall oral health.

For all individuals, it is important to visit the dentist for monitoring of general oral health, as well as denture assessment.

\section{Discussion}

Denture hygiene has not really changed to any extent for some decades. There have been few recent studies and little use of new technologies to investigate plaque removal and denture cleanser efficacy. The focus needs to be on removal of the prostheses for effective denture cleansing regimes involving both chemical soaks for penetration and loosening of plaque and calculus, combined with brushing to remove the biofilm from the denture surface. The development of new denture cleansing products and methods of use should address the different consumer groups (the active and debilitated elderly) of denture wearers.

There is a need for more large and comprehensive studies on the oral flora of the elderly. Current knowledge in the field often relies on older publications, using relatively few samples and targeting specific microorganisms. Modern molecular methods such as denaturing gradient gel electrophoresis have demonstrated differences in the total flora, cultivable and otherwise, from different sites on the denture, which, coupled with DNA sequencing, might enable further characterisation of the composition of denture plaque, and the identification of a less potentially 'pathogenic' denture plaque flora. Knowledge of denture plaque microbiology may contribute not only to better oral health but also to improved systemic health and well-being.

\section{References}

1 Pietrokovski J, Azuelos J, Tau S, Mostavoy R. Oral findings in elderly nursing home residents in selected countries: oral hygiene conditions and plaque accumulation on denture surfaces. J Prosthet Dent 1995; 73: 136-41.

2 Peltola P, Vehkalahti MM, Wuolijoki-Saaristo K. Oral health and treatment needs of the long-term hospitilised elderly. Gerodontology 2004; 21: 93-9.

3 de Visschere LM, Grooten L, Theuniers G, Vanobbergen JN. Oral hygiene of elderly people in long-term care institutions - a cross-sectional study. Gerodontology, 2006; 23: 195-204.

4 Locker D. Deprivation and oral health: a review. Community Dent Oral Epidemiol 2000; 28: 161-9.

5 McGrath C, Bedi R. The importance of oral health to older people's quality of life. Gerodontology, 1999; 16: 59-63.

6 Gil-Montoya J, Ferreria de Mello AL. Cardenas CB, Lopez IG. Oral health protocol for the dependent institutionalised elderly. Geriatr Nurs 2006; 27 (2): 95-101.

7 Mojon P, Budtz-Jorgensen E, Michel J-P, Limeback H. Oral health and history of respiratory tract infection in frail institutionalised elders. Gerodontology 1997; 14 (1): 9-16.
8 Talbot A, Brady M, Furlanetto DLC, Frenkel H, Williams BO. Oral care and stroke units. Gerodontology, 2005; 22: 77-83.

9 Thean $\mathrm{H}$, Wong ML, Koh H. The dental awareness of nursing home staff in Singapore - a pilot study. Gerodontology 2007; 24: 58-63.

10 Peltola P, Vehkalahti MM, Simoila R. Effects of 11-month interventions on oral cleanliness among the long-term hospitilised elderly. Gerodontology, 2007; 24 (1): 14-21.

11 Paillaud E, Merlier I, Dupeyron C, Scherman E, Poupon J, Bories $\mathrm{P}-\mathrm{N}$. Oral candidiasis and nutritional deficiencies in elderly hospitialised patients. Br J Nutr 2004; 92: 861-7.

12 Raghavendran K, Mylotte JM, Scannapieco FA. Nursing homeassociated pneumonia, hospital-acquired pneumonia and ventilator-associated pneumonia: the contribution of dental biofilms and periodontal inflammation. Periodontology 2000 2007; 44: 164-77.

13 El-Solh A, Sikka P, Ramadan F, Davies J. Etiology of severe pneumonia in the very elderly. Am J Respir Crit Care Med 2001; 163: 645-51.

14 Sumi Y, Miura H, Michiwaki Y, Shuichiro N, Nagaya M. Colonisation of dental plaque by respiratory pathogens in dependent elderly. Arch Gerontol Geriatr 2007; 44 (2): 119-24.

15 Centers for Disease Control and Prevention. Guidelines for prevention of nosocomial pneumonia, MMWR 1997; : 1-79.

16 Sumi Y, Miura H, Sunakawa M, Michiwaki Y, Sakagami N. Colonisation of denture plaque by respiratory pathogens in dependent elderly. Gerodontology, 2002; 19: 25-9.

17 Sumi Y, Kagami H, Ohtsuka Y, Kakinoki Y, Haruguchi Y, Miyamoto H. High correlation between the bacterial species in denture plaque and pharyngeal microflora. Gerodontology, 2003; 20 (2): 84-7.

18 Wellcome Focus. Ageing: can we stop the clock? www.wellcome.ac.uk/wellcomefocus, 2006.

19 Kelly M, Steele J, Nuttall N et al. Adult dental health survey: oral health in the United Kingdom 1998. The Government Statistical Service, 2000.

20 Oeppen J, Vaupel JW. Broken limits to life expectancy. Science 2002; 296: 1029-31.

21 Senpuku H, Sogame A, Inoshita E, Tsuha Y, Miyazaki H, Hanada H. Systemic diseases in association with microbial species in oral biofilm from elderly requiring care. Gerontology 2003; 49: 301-9.

22 Verran J. Malodour in denture wearers: an ill-defined problem. Oral Dis 2005; 11 (Suppl 1): 24-8.

23 Neill D. A study of materials and methods employed in cleaning dentures. Br Dent J 1968; 124 (3): 107-15.

24 Budtz-Jørgensen E. Prognosis of overdenture abutments in the aged: effect of denture wearing habits. Community Dent Oral Epidemiol 1992; 20: 302-6.

25 Budtz-Jørgensen E. Effects of denture-wearing habits on periodontal health of abutment teeth in patients with overdentures. J Clin Periodontol 1994; 21: 265-9.

26 Verran J. Denture plaque, denture stomatitis and the adhesion of Candida albicans to inert materials. In: Busscher HE ed. Oral biofilms and plaque control. Amsterdam: Harwood, 1999: 175-191.

27 Smith AJ, Brewer A, Kirkpatrick P et al. Staphylococcal species in the oral cavity from patients in a regional burns unit. J Hosp Infect 2003; 55: 184-9.

28 Lewis N, Ready D, Howlett J, Lee D, Cookson B, Wilson M. Culture-dependant detection of MRSA in angular chelitis. $J$ Dent Res 2006; 85 (Spec Issue C): Abstract 0401 www.dentalresearch.org.

29 Allison RT, Douglas WH. Micro-colonisation of the denturefitting surface by Candida albicans. J Dent 1973; 1 (5): 198-201. 
30 Verran J, Maryan CJ. Retention of Candida albicans on acrylic resin and silicone of different surface topography.J Prosth Dent 1997; 77: 535-9.

31 Bulad K, Taylor RL, Verran J, McCord JF. Colonization and penetration of denture soft lining materials by Candida albicans. Dent Mater 2004; 20: 167-75.

32 Price C, Williams DW, Waters MGJ et al. Reduced adherence of Candida to silane treated silicone rubber. J Biomed Mater Res B Appl Biomater 2005; 74: 481-7.

33 Zissis A, Yannikakis S, Harrison A. Comparison of denture stomatitis prevalence in 2 population groups. Int J Prosthodont 2006; 19 (6): 621-5.

34 Marsh P, Martin MV. Oral microbiology. Oxford: Wright, 1999.

35 Marsh PD. Microbial ecology of dental plaque and its significance in health and disease. Adv Dent Res 1994; 8 (2): 263-71.

36 Paster B, Boches SK, Galvin JL et al. Bacterial diversity in human subgingival plaque. J Bacteriol 2001; 183 (12): 3770-83.

37 Theilade E, Budtz-Jorgensen E, Theilade J. Predominant cultivable microflora of plaque on removable dentures in patients with healthy oral mucosa. Arch Oral Biol 1983; 28 (8): 675-80.

38 Gusberti F, Gada TG, Lang NP, Geering AH. Cultivable microflora of plaque from full denture bases and adjacent palatal mucosa. J Biol Buccale 1985; 13 (3): 227-36.

39 Theilade E, Budtz-Jorgensen E. Predominant cultivable microflora of plaque on removable dentures in patients with denture-induced stomatitis. Oral Microbiol Immunol 1988; 3: 8-13.

40 Socransky S, Manganiello SD. The oral microbiota of man from birth to senility. J Periodontol 1971; 42: 485-94.

41 Marsh PD. The oral microflora - friend or foe? Can we decide? Int Dent J 2006; 56 (4 [Suppl 1]): 233-9.

42 Kazor C, Mitchell PM, Lee AM et al. Diversity of bacterial populations on the tongue dorsa of patients with halitosis and healthy patients. J Clin Microbiol 2003; 41 (2): 558-63.

43 Wilson MJ, Weightman AJ, Wade WG. Applications of molecular ecology in the characterisation of uncultured microorganisms associated with human disease. Rev Med Microbiol 1997; 8: 91-101.

44 Wade W, Spratt DA, Dymock D, Weightman AJ. Molecular detection of novel anaerobic species in dentoalveolar abscesses. Clin Infect Dis 1997; 25 (Suppl 2): S235-236.

45 Nikawa H, Hamada T, Yamamoto T. Denture plaque - past and recent concerns. J Dent 1998; 26 (4): 299-304.

46 Marsh PD. Dental plaque as a microbial biofilm. Caries Res 2004; 38: 204-11.

47 Coulthwaite L, Pretty IA, Smith PW, Higham SM, Verran J. QLF of denture paque: red fluorescence has microbiological origin. J Dent Res 2005; 84 (Spec Issue B): Abstract 0093 www.dentalresearch.org

48 Verran J, Smith PW, Higham SM, Coulthwaite L. Comparison of methods for planimetric assessment of denture plaque. $J$ Dent Res 2006; 85 (Spec Issue C): Abstract 0523 www.dentalresearch.org

49 Sagal P, Lapujade PG, Miller JM, Sunberg RJ. Objective quantification of plaque using digital image analysis. In: Faller $\mathrm{R}$ ed. Assessment of oral health. Basal: Karger, 2000: 130-43.

50 Theilade J, Budtz-Jorgensen E. Electron microscopic study of denture plaque. J Biol Buccale 1980; 8: 287-97.

51 Budtz-Jørgensen E, Theilade E, Theilade J, Zander HA. Method for studying the development, structure and microflora of denture plaque. Scand J Dent Res 1981; 89 (2): 149-56.

52 Koopmans ASF, Kippuw N, de Graff J. Bacterial involvement in denture-induced stomatitis. J Dent Res 1988; 67 (9): 1246-50.
53 Budtz-Jørgensen E, Theilade E. Regional variations in viable bacterial and yeast counts of 1-week old denture plaque in denture induced stomatitis. Scand J Dent Res 1983; 91: 288-95.

54 Aas JA, Paster BJ, Stokes LN, Olsen I, Dewhirst FE. Defining the normal bacterial flora of the oral cavity. J Clin Microbiol 2005; 43 (11): 5721-32.

55 Harding S, Wilson M, Dickinson C, Hobkirk J. The cultivable microflora of denture plaque from patients with dentureinduced stomatitis. Microbial Ecol Health Dis 1991; 4: 149-57.

56 Coulthwaite L, Verran J. Denture plaque: a neglected biofilm. In: Allison D, Verran J, Spratt D, Upton M, Pratten J, McBain A eds. Biofilms: persistence and ubiquity. Manchester: The Biofilm Club, 2005: 311-22.

57 Verran J. Preliminary studies on denture plaque microbiology and acidogenicity. Microbial Ecol Health Dis 1988; 1: 51-5.

58 Coulthwaite L, Smith PW, Higham SM, Verran J, Detection of bacterial populations in denture plaque using DGGE. J Dent Res 2006; 85 (Spec Issue C): Abstract 0522, www.dentalresearch.org

59 Gafan G, Lucas V, Wilson M, Spratt D. Community analysis of the microflora of dental plaque associated in health and gingivitis via a denaturing gradient gel electrophoresis approach. In: McBain A, Allison D, Brading M, Rickard A, Verran J, Walker J eds. Biofilm communities: order from chaos? Cardiff: BioLine, 2003: 155-64.

60 Siqueira J, Rocas IN, Rosado AS. Investigation of bacterial communities associated with asymptomatic and symptomatic endodontic infections by denaturing gradient gel electrophoresis fingerprinting approach. Oral Microbiol Immunol 2004; 19: 363-70.

61 Verran, J, Rocliffe MD. Feasibility of using automatic image analysis for measuring dental plaque in situ. J Dent 1986; 14: 11-3.

62 Cardash H, Rosenberg M. An innovative method of monitoring denture hygiene. J Prosth Dent 1990; 63 (6): 661-4.

63 Soder P.-O, Jin LJ, Soder B. Computerized planimetric method for clinical plaque measurement. Scand J Dent Res 1993; 101: 21-5.

64 McCabe J, Murray DI, Kelly PJ. The efficacy of denture cleansers. Eur J Prosthodont Restor Dent 1995; 3 (4): 203-7.

65 Shaloub A, Addy M. Evaluation of accuracy and variability of scoring-area-based plaque indices. J Clin Periodont 2000; 27: 16-21.

66 Sheen S, Harrison A. Assessment of plaque prevention on dentures using an experimental cleanser. J Prosth Dent 2000; 84 (6): 594-601.

67 Qin X, Luan XL, Bi LJ et al. Real-time detection of dental calculus by blue LED-induced fluorescence spectroscopy. J Photochem Photobiol B Biol 2007; 87: 88-94.

68 Van der Veen M, de Josselin de Jong E. Application of quantitative light-induced fluorescence for assessing early caries lesions. In: Faller R ed. Assessment of oral health. Basal: Karger, 2000: 144-62.

69 Pretty I, Edgar WM, Smith PW, Higham SM. Quantification of dental plaque in the research environment. J Dent 2005; 33: 193-207.

70 Coulthwaite L, Pretty I, Smith PW, Higham SM, Verran J. The microbiological origin of red fluorescence observed in denture plaque during QLF analysis. Caries Res 2006; 40 (2): 112-6.

71 Davenport J. The oral distribution of Candida in denture stomatitis. Br Dent J 1970; 129: 151-6.

72 Budtz-Jørgensen E. The significance of Candida albicans in denture stomatitis. Scand J Dent Res 1974; 82: 151-90.

73 Arendorf TM, Walker DM. The prevalence and intra-oral 
distribution of Candida albicans in man. Arch Oral Biol 1980; 25: 1-10.

74 Odds F. Candida and candidosis 2nd edn. London: Bailliere Tindall, 1988.

75 Mitchell TG. Medical mycology. In: Brooks G, Butel JS, Morse SA eds. Jawetz, Melnick \& Adelberg's Medical Microbiology. London: McGraw Hill, 2001.

76 Douglas LJ. Adhesion of Candida albicans to host surfaces. In: Tumbay E, Seeliger HPR, Ang O eds. Candida and candidamycosis. New York: Plenum Press, 1991.

77 Verran J, Melvin J, Coulthwaite L. Adhesion of Candida spp. from denture plaque to epithelial cells. J Dent Res 2007; 86 (Spec Issue B): Abstract 0077, www.dentalresearch.org

78 Arendorf TM, Walker DM. Denture stomatitis: a review. J Oral Rehabil 1987; 14 (3): 217-27.

79 Samaranayake LP. Host factors and oral candidosis. In: Samaranayake LP, MacFarlane TW eds. Oral candidosis. London: Butterworth, 1990.

80 Simons D, Kidd, EAM, Beighton D. Oral health of elderly occupants in residential homes. Lancet 1999; 353: 1761.

81 Kulak-Ozkan Y, Kazazoglu E, Arikan A. Oral hygiene habits, denture cleanliness, presence of yeasts and stomatitis in elderly people. J Oral Rehabil 2002; 29: 300-4.

82 Webb B, Thomas CJ, Harty DWS, Willcox MDP. Effectiveness of two methods of denture sterilisation. J Oral Rehabil 1998; 25: 416-23.

83 Olsen I. Denture stomatitis: occurence and distribution of fungi. Acta Odontol Scand 1974; 32: 329-33.

84 Budtz-Jørgensen E. Etiology, pathogenesis, therapy and prophylaxis of oral yeast infections. Acta Odontol Scand 1990; 48: 61-9.

85 Fiske J, Davis DM, Horrocks P. A self-help group for complete denture wearers. Br Dent J 1995; 178 (1): 18-22.

86 Tonzetich J. Production of oral malodor: a review of the mechanisms and methods of analysis. J Periodontol 1977; 48 (1): 13-20.

87 Rolla G, Waaler SM, Kjaerheim V. Concepts in dental plaque formation. In: Busscher HE ed. Oral biofilms and plaque control. Amsterdam: Harwood Academic, 1999: 1-17.

88 Mink R, Biemer TA, Pianotti RS, Dills SS. Volatile sulphur compound production in anaerobic oral bacteria. J Dent Res 1983; 62 (Spec Issue Abstract 91): 180.

89 Socransky S, Haffajee AD, Smith C et al. Use of checkerboard DNA-DNA hybridisation to study complex microbial ecosystems. Oral Microbiol Immunol 2004; 19: 352-62.
90 Krespi YP, Schrime MG, Kacker A. The relationship between oral malodor and volatile sulfur compound-producing bacteria. Otolaryngol Head Neck Surg 2006; 135: 671-6.

91 Berbari E, Cockerill FR, Steckelberg JM. Infective endocarditis due to unusual or fastidious microorganisms. Mayo Clin Proc 1997; 72: 532-42.

92 Abe S, Ishihara K, Adachi M, Okuda K. Oral hygiene evaluation for effective oral care in preventing pneumonia in dentate elderly. Arch Gerontol Geriatr 2006; 43: 53-64.

93 Scannapieco FA. Role of oral bacteria in respiratory infection. J Periodontol 1999; 70 (7): 793-802.

94 Scannapieco FA. Pneumonia in non-ambulatory patients. J Am Dent Assoc 2006; 137 (10 Suppl): 21S-25S.

95 Budtz-Jørgensen E, Bertram V. Denture stomatitis I: The etiology in relation to trauma and infection. Acta Odontol Scand 1970; 28: 71-92.

96 Abelson D. Denture plaque and denture cleansers. J Prosth Dent 1981; 45 (4): 376-9.

97 Nakamoto K, Tamamoto M, Hamada T. Evaluation of denture cleansers with and without enzymes against Candida albicans. J Prosth Dent 1991; 66 (6): 792-5.

98 Tarbet W, Axelrod S, Minkoff S, Fratarcangelo PA. Denture cleansing: a comparrison of two methods. J Prosth Dent 1984; 51: $322-5$.

99 Loe H, Theilade E, Jensen SB. Experimental gingivitis in man. J Periodontol 1965; 36: 177-87.

100 Dikbas I, Koksal T, Calikkocaoglu S. Investigation of the cleanliness of dentures in a university hospital. Int J Prosthodont 2006; 19 (3): 294-8.

101 British Dental Association. www.bda.org

102 Abelson D. Denture plaque and denture cleansers: review of the literature. Gerodontics 1985; 1: 202-6.

103 Gwinnett A, Caputo L. The effectiveness of ultrasonic denture cleaning: a scanning electron microscope study. J Prosth Dent 1983; 50: 20-5.

104 Budtz-Jørgensen E. Materials and methods for cleaning dentures. J Prosth Dent 1979; 42 (6): 619-23.

105 Dills S, Olshan AM, Goldner S, Brogdon C. Comparison of the antimicrobial capability of an abrasive paste and chemical-soak denture cleaners. J Prosth Dent 1988; 60: 467-70.

106 Coulthwaite L, Sultula J, Smith R, Verran J. Susceptibility of in vitro model denture plaque biofilms to denture cleansers. J Dent Res 2007; 86 (Spec Issue B): Abstract 0241, www.dentalresearch.org 